\title{
Phenotype in patients with Angelman syndrome
}

The excellent report by Gillessen-Kaesbach et $\mathrm{al}^{1}$ on seven patients with a consistent phenotype which is unusual for Angelman syndrome reinforces the emerging notion that features resembling those of Prader-Willi syndrome can be associated with molecular defects classically leading to the former but not the latter. In addition to these patients and the references cited in the paper, another girl with clinical features resembling Prader-Willi syndrome, inversion-duplication of $15 q$ and absence of maternal methylation pattern was recently described Dupont et al. ${ }^{2}$ In the same context, it should be noted that the partial paternal disomy mouse model for Angelman syndrome shows obesity as a consistent characteristic. $^{3}$ Reviewing earlier literature, one may find striking similarities between the patients reported by Gillessen-Kaesebach and the condition described by Clara and Lowenthal in four siblings. ${ }^{4}$ These patients had cystinuria in association with features somewhat suggestive of Prader-Willi syndrome, and recent reappraisal of their diagnosis failed to show cytogenetically detectable 15q11 deletions (Jaeken, personal communication). However, this might prompt to search for imprinting defects of the critical region for Angelman syndrome in these Belgian patients as well as for cystinuria in the German patients.

Bernard Dan, MD

Department of Neurology, University Children's Hospital Queen Fabiola, Brussels, Belgium
2 Dupont JM, Le Tessier D, Rabineau D et al: Unexpected Angelman syndrome molecular defect in a girl displaying clinical features of Prader-Willi syndrome. J Med Genet 1999; 36: 652-654.

3 Cattanach BM, Barr JA, Beechey CV, Martin J, Norbels J, Jones J: A candidate model for Angelman syndrome in the mouse. Mamm Genome 1997; 8: 472-478.

4 Clara R, Lowenthal A: Aminoacidurie tubulaire congénitale et familiale avec nanisme grave et hypotonie musculaire à évolution favorable chez quatre enfants d'une même fratrie. Acta Neurol Psychiatr Belg 1965; 65: 911-936.

\section{Reply to letter from B Dan}

We appreciate the interesting comments on the report by Gillessen-Kaesbach et al. We agree that the Angelman syndrome (AS) patient described by Dupont et al displays a similar phenotype in comparison with the patients with AS due to an imprinting defect. However, neither the mouse model described by Cattanach et al nor the other AS patients resolve the question of why obesity is present in these patients.

Indeed, the siblings reported by Clara and Lowenthal should be tested by methylation analysis at the SN RPN locus. It is tempting to speculate that our patients might turn out to have cystinuria.

Gabriele Gillessen-Kaesbach Bernhard Horsthemke Institut für Humangenetik, Universitätsklinikum Essen, Germany

\section{References}

1 Gillessen-Kaesbach G, Demuth S, Thiele H, Theile U, Lich C, Horsthemke B: A previously unrecognised phenotype characterised by obesity, muscular hypotonia and ability to speak in patients with Angelman syndrome caused by an imprinting defect. Eur J Hum Genet 1999; 7: 638-644. 